\title{
Evaluation of different DNA extraction methods and loop-mediated isothermal amplification primers for the detection of Mycobacterium ulcerans in clinical specimens
}

Anthony Ablordey ${ }^{1 *}$ (D), Evans Ahotor ${ }^{1}$, Charles A. Narh ${ }^{1}$, Sandra A. King ${ }^{1}$, Isra Cruz ${ }^{2,3}$, Joseph M. Ndung' ${ }^{2}$ and Dziedzom K. de Souza ${ }^{1,2}$

\begin{abstract}
Background: Early diagnosis and treatment of Buruli ulcer is critical in order to avoid the debilitating effects of the disease. In this regard, the development of new diagnostic and point of care tools is encouraged. The loopmediated isothermal amplification for the detection of Mycobacterium ulcerans represents one of the new tools with a good potential of being developed into a point of care test. There is however the need to standardize the assays, reduce sample preparation times, improve the detection/visualization system and optimize them for highthroughput screening, adaptable to low resourced laboratories.

Methods: In this study, we assessed two DNA extraction protocols (modified Boom and EasyNAT methods), three previously published LAMP primer sets (BURULI, MU 2404 and BU-LAMP), and compared the sensitivity and specificity of LAMP assays on three DNA amplification platforms.

Results: Our results show that Buruli ulcer diagnosis using primers targeting IS2404 for the LAMP method is sensitive (73.75-91.49\%), depending on the DNA extraction method used. Even though the modified Boom DNA extraction method provided the best results, its instrumentation requirement prevent it from being field applicable. The EasyNAT method on the other hand is simpler and may represent the best method for DNA extraction in less resourced settings.
\end{abstract}

Conclusions: For further work on the development and use of LAMP tests for Buruli diagnosis, it is recommended that the BURULI sets of primers be used, as these yielded the best results in terms of sensitivity (87.50-91.49\%) and specificity (89.23-100\%), depending on the DNA extraction methods used.

Keywords: Loop mediated isothermal amplification, DNA extraction, Sensitivity, Specificity

\footnotetext{
* Correspondence: aablordey@noguchi.ug.edu.gh

${ }^{1}$ Noguchi Memorial Institute for Medical Research, College of Health Sciences, University of Ghana, Legon, Accra, Ghana

Full list of author information is available at the end of the article
}

(C) The Author(s). 2021 Open Access This article is licensed under a Creative Commons Attribution 4.0 International License, which permits use, sharing, adaptation, distribution and reproduction in any medium or format, as long as you give appropriate credit to the original author(s) and the source, provide a link to the Creative Commons licence, and indicate if changes were made. The images or other third party material in this article are included in the article's Creative Commons licence, unless indicated otherwise in a credit line to the material. If material is not included in the article's Creative Commons licence and your intended use is not permitted by statutory regulation or exceeds the permitted use, you will need to obtain permission directly from the copyright holder. To view a copy of this licence, visit http://creativecommons.org/licenses/by/4.0/ The Creative Commons Public Domain Dedication waiver (http://creativecommons.org/publicdomain/zero/1.0/) applies to the data made available in this article, unless otherwise stated in a credit line to the data. 


\section{Background}

Buruli ulcer (BU) caused by Mycobacterium ulcerans is a necrotizing skin disease endemic in several rural communities in sub-Saharan Africa, particularly in Cote d'Ivoire, Ghana and Benin. There are also other foci of $\mathrm{BU}$ in the Americas, as well as in Asia and Oceania, with a very sharp recent increase in the number of cases in Australia in recent years. BU is the third most prevalent mycobacterial disease after tuberculosis [1-3]. Due to poor understanding of its epidemiology and transmission, there are no effective primary preventive measures for control of the disease. Control efforts focus on early case detection and prompt treatment to stop progression to the ulcerative stages, and thus avoid the associated disabilities [4].

Absence of effective diagnostic services accounts for the poor surveillance of the disease $[5,6]$. In rural areas where majority of cases are detected, samples are often sent to reference laboratories for confirmatory testing, which takes 1-2 weeks. District hospitals rely on clinical diagnosis, but this is often inaccurate and complicated by other disease conditions with similar presentations, leading to misdiagnosis. Microscopic examination detects $29-78 \%$ of clinically suspected BU cases and is currently the only rapid and affordable test available for BU diagnosis in many endemic areas [6]. The detection rate of culture is between 34 and $79 \%$ and takes an average of 9-12 weeks to yield positive results but this too is only available in reference labs [6]. Culture therefore cannot be used for rapid laboratory confirmation. Histopathological examinations reportedly detect $30 \%$ additional cases than other confirmatory tests, however these techniques are restricted to external reference laboratories and are unavailable in peripheral health centres, district or regional hospitals [6]. These challenges; including poor conditions for sample transportation, and long turnaround times, contribute to late treatment and management of the disease. The WHO's Second International Conference on Buruli Ulcer Control and Research resolved to strengthen the capacity of national laboratories to confirm cases of the disease but warned that "efforts are still needed to develop simple diagnostic tools usable in the field as well as disability prevention methods" [7]. Therefore, new field applicable techniques for the diagnosis of $\mathrm{BU}$, paralleling PCR in sensitivity and specificity, need to be developed $[2,6]$.

IS2404 PCR has close to $96 \%$ sensitivity and has been recommended by WHO for laboratory confirmation of BU [8-13]. However, PCR is labour intensive, expensive and unsuited for use in rural African settings with poorly resourced labs [14]. Isothermal amplification of nucleic acids in recent times has been relied upon to circumvent the limitations of traditional PCR and provides a platform that can support the development of rapid Point of
Care (POC) molecular diagnostic tests [15]. Loopmediated isothermal amplification (LAMP) is a method that amplifies DNA with high specificity, sensitivity and rapidity at a constant temperature. The method utilizes the strand displacement ability of the Bacillus stearothermophilus DNA polymerase (Bst polymerase) to loop 4-6 primer pairs, including inner and outer primers, to the target loci of interest. Thus, it yields several stem-loop amplicons, which sustains the reaction cycling at 60$65^{\circ} \mathrm{C}$. The main advantage of LAMP over PCR is that it does not require thermal cyclers and gel imaging equipment, and thus, amplification can be performed within an hour or less in a laboratory with a heat block or water bath $[8,16]$. LAMP reaction results can be visualised with the naked eye from colorimetric changes following addition of intercalating fluorescent dyes such as SYBR green or hydroxynapthol blue (HNB) to reaction tubes, pre- or post-reaction [17]. LAMP is also less inhibited by contaminants within the sample and the closed tube approach reduces problems of cross contamination. It has been widely developed for detection of various disease pathogens, including viral, bacterial and protozoan [18-22]. The superiority of LAMP, cost-effectiveness and ease of use by potential 'unskilled' personnel makes it an attractive molecular diagnostic tool to further develop for clinical use, particularly in resource-limited settings where PCR cannot be afforded.

Previous studies developed LAMP assays for the detection of Mycobacterium ulcerans in clinical samples $[8,16,23]$. Separately, two of the primers (Table 1) amplified fragments of the multi-copy insertion sequence, IS2404, of which 214 copies are present in the genome of the bacterium [8, 23], while the other amplified another insertion sequence, IS2606, with about 60 genomic copies present [16]. The results showed superior sensitivity of LAMP to PCR [8, 16, 23]. However, the sample sizes used in these investigations were small and different methods were used, which did not allow accurate comparisons of the data. Hence, there was a need to standardize the assays, reduce sample preparation times, improve the detection/visualization system, and optimize them for high-throughput screening, adaptable to low resourced laboratories. To reduce the turnaround times, we utilized and compared two rapid DNA extraction protocols for sample preparation. Using several clinical samples from endemic communities, we compared the sensitivity and specificity of LAMP assays on three DNA amplification platforms. Three recommended fluorescent dyes were also optimized and used to visualize test results. We present comparative genomic DNA extraction and primer-specific LAMP data that provide suitable alternatives with remarkable sensitivity for rapid diagnosis of BU. 


\section{Methods}

\section{Work flow}

The flow diagram of the study is shown in Fig. 1.

\section{Samples}

The samples used in this study were archived as well as fresh patient's samples. Fresh samples were collected from consenting patients attending Buruli ulcer Clinic at selected district hospitals and health centres in Ghana, using the Fine Needle Aspiration (FNA) and Swabs methods [24, 25]. The Noguchi Memorial Institute for Medical Research (NMIMR) is one of the two reference centres in Ghana where patients' samples are sent for confirmation. As such, these samples were also included in the study. Swabs and FNAs were respectively put into sterile $15 \mathrm{ml}$ falcon tubes and phosphate buffered saline, and transported in cool box to NMIMR.

\section{DNA extractions}

Previous results indicated that crude DNA preparations yield low sensitivity compared with purified extracts in the LAMP assay [8]. Consequently, crude DNA extracts were not included in this work. In order to simplify DNA extraction for the LAMP test in field settings, two simple and rapid extraction protocols were used; a commercially available syringe silica membrane method (EasyNAT) for the extraction of $M$. tuberculosis DNA from sputum, and a modification of the syringe silica method (modified EasyNAT).

\section{Modified Boom extraction}

Portions $(250 \mu \mathrm{l})$ of the sample suspension were lysed with $250 \mu \mathrm{l}$ of lysis buffer $(1.6 \mathrm{M}$ guanidinum $\mathrm{HCl}, 60$ $\mathrm{mM}$ Tris (pH 7.4), 1\% Triton X-100, 60 mM EDTA, 10\% Tween-20), $50 \mu \mathrm{l}$ of Proteinase $\mathrm{K}(20 \mathrm{mg} / \mathrm{ml})$ and $500 \mu \mathrm{l}$ glass beads in a sterile $1.5 \mathrm{ml}$ tube. The mixture was incubated horizontally in an orbital shaker $(200 \mathrm{rpm})$ at $60{ }^{\circ} \mathrm{C}$ for $12 \mathrm{~h}$. To capture the DNA, $40 \mu \mathrm{l}$ of diatomaceous earth solution was added to the lysed sample and incubated at $37^{\circ} \mathrm{C}$ for $1 \mathrm{~h}$. The mixture was then centrifuged at $14000 \mathrm{rpm}$ for $1 \mathrm{~min}$ and the supernatant discarded. Pelleted DNA bound to the diatomaceous earth was washed twice with $900 \mu \mathrm{l}$ of ice cold $70 \%$ ethanol and $900 \mu \mathrm{l}$ of absolute acetone, pulsed vortexed and centrifuged at $14000 \mathrm{rpm}$ for 60s. The supernatant was discarded and DNA bound to diatomaceous earth was dried at $50{ }^{\circ} \mathrm{C}$ for $20 \mathrm{~min}$ using a heat block. DNA was re-suspended in $80 \mu \mathrm{l}$ of nuclease free water, incubated at $68^{\circ} \mathrm{C}$ for $20 \mathrm{~min}$ to release the DNA from the diatomaceous earth. The DNA extract was centrifuged at $14000 \mathrm{rpm}$ for $2 \mathrm{~min}$ and about $60 \mu \mathrm{l}$ of the resultant supernatant transferred to a sterile tube and kept at $-20{ }^{\circ} \mathrm{C}$. Negative and positive controls were included in each batch of DNA extraction. The negative control included all the reagents for DNA extraction, but excluding a clinical specimen, while the positive control included $250 \mu \mathrm{l}$ of $M$. ulcerans culture in suspension.

\section{Genomic DNA extraction using disposable silica syringe DNA extraction device (EasyNAT)}

DNA was extracted from suspension of clinical samples following the instructions provided by the manufacturer (USTAR Biotechnologies Ltd., Hangzhou, China). Briefly, $500 \mu \mathrm{l}$ of clinical specimen was pipetted into $1.5 \mathrm{~mL}$ tube, then $600 \mu \mathrm{l}$ of lysis buffer and $50 \mu \mathrm{l}$ Proteinase $\mathrm{K}$ were added. The mixture was incubated at $60^{\circ} \mathrm{C}$ for $30 \mathrm{~min}$ and allowed to cool to room temperature. $1400 \mu \mathrm{l}$ of absolute ethanol was added to the lysed clinical specimen, and the tube was inverted 3-4 times. The mixture was aspirated through the nozzle of an assembled silica syringe device (SSD), with the aid of the attached plunger. The lysed sample was slowly sucked back into the tube, leaving the

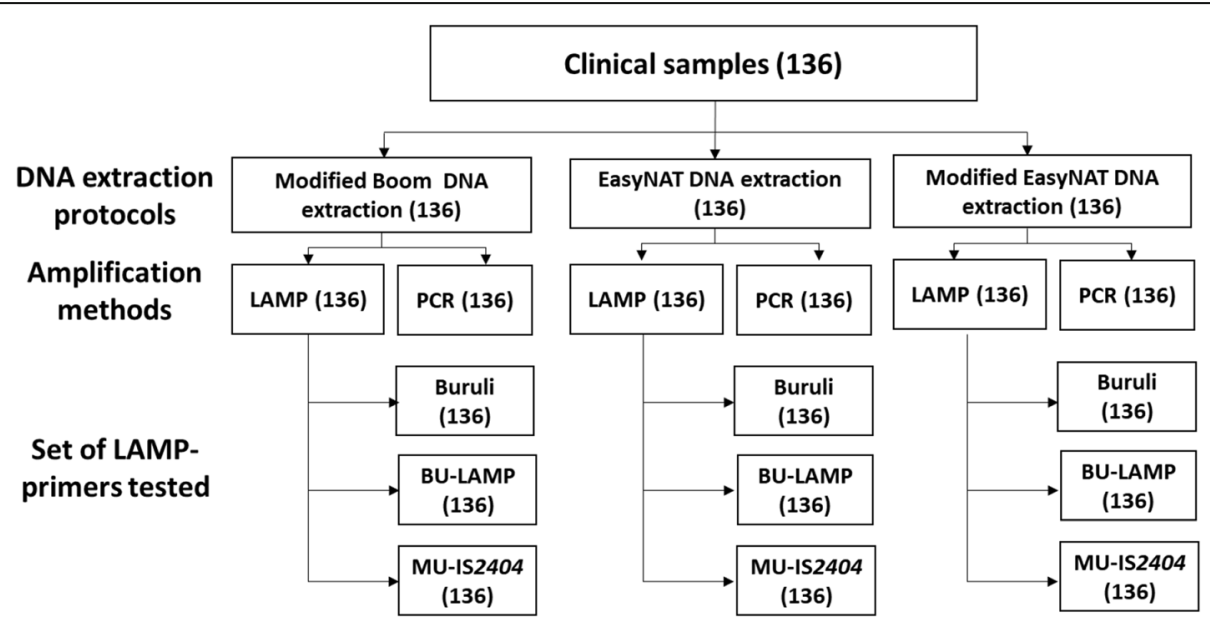

Fig. 1 Flow diagram of study procedure showing assays performed and the total number of samples tested 
DNA bound to the silica membrane at the base of the syringe. The DNA bound to the silica membrane was washed twice by sucking $60 \%$ of absolute ethanol through the nozzle of the syringe and slowly expelled. At this step, the DNA remained bound to the silica membrane. The $5 \mathrm{ml}$ syringe barrel was detached from the SSD and replaced with a $1 \mathrm{ml}$ syringe barrel (included in the kit). $100 \mu \mathrm{l}$ of nuclease free water was sucked and allowed to soak the silica membrane for $2 \mathrm{~min}$. The dissolved DNA was eluted into a $1.5 \mathrm{ml}$ tube.

\section{Genomic DNA extraction using a modified EasyNAT protocol}

Suspension of clinical sample $(150 \mu \mathrm{l})$ was lysed by adding $600 \mu \mathrm{l}$ of lysis buffer $(1.6 \mathrm{M}$ guanidinum $\mathrm{HCl}$, 60mMTris (pH 7.4), 1\% Triton X-100, 60 mM EDTA, $10 \%$ Tween 20) and $50 \mu \mathrm{l}$ Proteinase $\mathrm{K}(20 \mathrm{mg} / \mathrm{ml})$. The mixture was incubated at $60^{\circ} \mathrm{C}$ for $30 \mathrm{~min}$ and allowed to cool to room temperature. Absolute ethanol $(1400 \mu \mathrm{l})$ was added to the lysed sample, vortexed and sucked through the assembled silica syringe device (SSD) with the aid of the plunger. The lysed sample was then filtered back to the tube by pushing the plunger slowly. DNA bound to the silica membrane at the base of the SSD was washed twice with $2 \mathrm{ml}$ of $60 \%$ alcohol using air pressure generated from pushing the plunger. The $5 \mathrm{ml}$ syringe barrel was detached from the SSD and replaced with $1 \mathrm{ml}$ syringe barrel for DNA elution. Nuclease free water $(100 \mu \mathrm{l})$ was then sucked through the nozzle of the syringe. With the aid of the plunger, nuclease free water was sucked over the silica membrane 3-4 times and finally eluted in a $1.5 \mathrm{ml}$ eppendorf tube.

\section{Nucleic acid amplifications}

All DNA samples were tested with IS2404 PCR reference method [13]. The primer sequences for the IS2404 PCR is shown in Table 1. All published LAMP primer sets (Table 2) were tested on the different DNA extracts, in order to determine their sensitivity. LAMP assays were performed using the Loopamp DNA amplification kit (Eiken Chemical). For specificity, the primers were also tested on $M$. nonchromogenicum, M. fluoranthenivorans, M. fortuitum, M. porcinum, M. mucogenicum, M. ulcerans, and M. tuberculosis.

Table 1 IS2404 nested PCR primers

\begin{tabular}{lll}
\hline Primers & Sequence (5'-3') & $\begin{array}{l}\text { Expected Amplicon } \\
\text { size (bp) }\end{array}$ \\
\hline pGp1 & AGGGCAGCGCGGTGATACGG & 518 \\
pGp2 & CAGTGGATTGGTGCCGATCGAG & \\
pGp3 & GGCGCAGATCAACTTCGCGGT & 212 \\
pGp4 & CTGCGTGGTGTTTACGCGC & \\
\hline
\end{tabular}

Table 2 LAMP primers from the three different studies Ablordey et al, 2012 [8] Buruli-FIP:GTGCGCCGTGTCCGGTATGGATACGCGATGTCACCTTC Buruli- BIP: AGGTCCTAGCAACGCTACGCAAATCCGGCAGGCTTCGG Buruli-LF: GCCTTTGACGGTCTTCGTC Buruli- LB: CACCGCGATCAATCTGCAC Buruli- F3: CGAGAACAGCCTGCACTG Buruli- B3: CGGTTGGCGGTCAAAGC

Njiru et al, 2012 [23]

MU2404-FIP: CGTCGCGTATCCAGTGCAGGTCATGACCTGGATGCGTCA MU2404-BIP: GCGCACAGGTCCTAGCAACGGCTTCGGCGATGTTGTCG MU2404-F3:GCCTGCCGTTCGAGCA MU2404-B3:GTCAAAGCGGTGATCCGG MU2404-FLP:TTCTCGATTCCGCAGTG MU2404-BLP:GCAACACCGCGATCAATCTG

de Souza et al, 2012 [16]

BU-LAMP FIP: GCATCTCCGGCCACCCCAACGCCCAACGACCGCTA BU-LAMP BIP:GTGGTGGGCCCCTGGGAAACCGCTGTCGAACTGTGC BU-LAMP F3: ACGGATCGTCGAGGATGG

BU-LAMP B3:GCGCCAGGTCCCTTGA

BU-LAMP FLP:GAGCCTGCTGGGCGGTC BU-LAMP BLP: CAGATCCCACCCTGGTG

\section{Preparation of suspensions containing different copy numbers of IS2404 for determination of the detection limit of the LAMP tests}

A single colony of $M$. ulcerans growing on LowensteinJensen media slant was harvested in nuclease free water. DNA was extracted from this culture using the QIAG EN DNeasy Blood \& Tissue Kits (QIAGEN, California). The concentration of the final extract was $0.2 \mathrm{ng} / \mu \mathrm{l}$ (stock concentration in a final volume of $20 \mu \mathrm{l}$ ), which was equivalent to 300,000 copies of IS2404. The latter was serially diluted in a volume of $20 \mu$ l to contain 30, 000, 3000, 300, 30 and 3 copies of IS2404. LAMP assays were performed on these dilutions to measure the detection limit of the three primer sets.

\section{Optimization of visualization system for M. ulcerans}

The detection of LAMP amplicons can utilize several intercalating fluorescent dyes [17], which suggests that an optimum dye concentration will increase the detection limit. In this study, we also compared two dyes; Calcein and HNB using protocols described elsewhere [17, 26]. This was done in closed tubes to prevent possible cross-contamination. Calcein turns from yellow (negative test) to fluorescent green (positive test) and hydroxynapthol blue turns from violet (negative test) to sky blue (positive test). 


\section{Data analysis}

For data analysis, $2 \times 2$ contingency tables were generated for the evaluation of diagnostic accuracy. The data was analysed for diagnostic test evaluation using MedCalc Software (Version 18.6). The disease prevalence, sensitivity, specificity, positive and negative predictive values as well as accuracy, were expressed as percentages, with their corresponding 95\% confidence intervals.

\section{Results}

\section{Comparison of DNA extraction protocols}

Results of IS2404 PCR performed on the three different DNA extracts is shown in Table 3 below. A total of 136 extracts were analysed. The modified Boom DNA extraction method gave the highest PCR positivity (69.12\%), followed by the EasyNAT DNA extraction method (58.82\%).

\section{Sensitivity and specificity of LAMP assays in combination with different DNA extracts}

The results of the various tests were compared for their sensitivity, specificity and predictive values and accuracy (Table 4). For this, the IS2404 PCR was used as the reference standard. For a particular LAMP assay and with a particular DNA extract, more positives were detected with the BURULI primer set designed by Ablordey [8], followed by the MU 2404 primers of Njiru [23] and then MU LAMP primers of de Souza [16] (Table 4). Specificity however did not follow a similar pattern. Across corresponding tests, the LAMP test on Boom extracts yielded the most number of positives followed by EasyNAT and then the modified EasyNAT extracts. However positivity of the LAMP test for modified and unmodified extracts where the same. For the modified Boom, EasyNAT and modified DNA extracts, the BURULI primers yielded sensitivities of $91.49,87.50$ and $90.14 \%$, and specificities of $97.26,100.00$ and $89.23 \%$ respectively. The MU 2404 primers yielded sensitivities of 86.12, $73.75,83.10 \%$ and specificities of $88.10,98.21$ and $93.85 \%$ respectively. The BU-LAMP primers on the other hand yielded the lowest sensitivities of 57.45, 47.50, 35.21\% and highest specificities of 100.00, 98.21 and $95.38 \%$ respectively. Thus, comparing the trade off between sensitivity and specificity, coupled with the predictive values and the accuracies, the BURULI primers gave the best results.
Across corresponding tests, sensitivity was highest for the LAMP test on Boom extracts (57.45-91.49\%), followed by the modified EasyNAT (35.21-90.14\%) and then unmodified EasyNAT extracts (47.50-87.50\%). Specificity did not follow a specific pattern, but the values were high (88.1-100\%). The results also showed the EasyNAT method to have a high specificity $(98.2-100 \%)$ i.e. the probability of screening negative if the disease is truly absent. On the other hand, the modified EasyNAT method had the lowest sensitivities (35.21-90.14\%) i.e. the probability of screening positive if the disease is truly present. The predictive values of the various tests were also estimated. The positive predictive value, which estimates the probability that an individual actually has the disease given a positive test, varied according to the methods.

The detection limit of the LAMP test was 30 copies of IS2404. However half and a quarter of the tests were positive for BURULI and MU 2404 primers respectively (Table 5). Concerning the specificity of the tests, the results revealed that, of the eight Mycobacterium species tested with the three sets of primers, only $M$. ulcerans isolates tested positive in the LAMP test.

\section{Comparison of fluorescence detection dyes}

The optimization of a fluorescent dye system was undertaken using the BURULI and MU 2404 primers. For a given test (BURULI or MU 2404), no significant difference was found between tests performed using calcein or HNB. (Table 6).

\section{Discussions}

This study revealed that the efficiency of the LAMP reaction depends on the quality of extracted DNA and the efficiency of the primers used. We compared the sensitivities and specificities of the various tests, as well as their predictive values, using IS2404 PCR as the gold standard. In deciding upon the criteria for acceptable levels of specificity and sensitivity, it is important to consider the consequences of leaving cases undetected (false negatives) against the false classification of healthy individuals as infected (false positives) [27]. In the context of $\mathrm{BU}$ diagnosis, in the absence of other options, the sensitivity of a diagnostic method should be increased at the expense of specificity, since the penalty associated with missing a case is high. Our results indicated that the

Table 3 PCR analysis of 136 clinical samples. Values in brackets represent the 95\% Cl

\begin{tabular}{|c|c|c|c|c|c|c|}
\hline \multirow[t]{2}{*}{ Sample } & \multicolumn{2}{|c|}{$\begin{array}{l}\text { PCR on } \\
\text { Modified Boom DNA Extract }\end{array}$} & \multicolumn{2}{|c|}{$\begin{array}{l}\text { PCR on } \\
\text { Modified EasyNAT DNA extract }\end{array}$} & \multicolumn{2}{|c|}{$\begin{array}{l}\text { PCR on } \\
\text { EasyNAT DNA extract }\end{array}$} \\
\hline & +ve & -ve & + ve & -ve & $+\mathrm{ve}$ & -ve \\
\hline 136 & 94 & 42 & 71 & 65 & 80 & 56 \\
\hline Positivity \% & \multicolumn{2}{|c|}{$69.12(60.63-76.75)$} & \multicolumn{2}{|c|}{$52.21(43.48-60.84)$} & \multicolumn{2}{|c|}{$58.82(50.07-67.19)$} \\
\hline
\end{tabular}


Table 4 Comparison of sensitivity and specificity of three LAMP tests based on calcein visualization with different DNA extracts. Values in brackets represent the 95\% Cl

\begin{tabular}{|c|c|c|c|c|c|c|c|c|c|}
\hline & \multicolumn{9}{|c|}{ LAMP WITH MODIFIED BOOM DNA EXTRACTS } \\
\hline & \multicolumn{3}{|c|}{ BURULI Primers } & \multicolumn{3}{|c|}{ MU 2404 Primers } & \multicolumn{3}{|c|}{ BU-LAMP Primers } \\
\hline & $(+)$ & $(-)$ & Total & $(+)$ & $(-)$ & Total & $(+)$ & $(-)$ & Total \\
\hline IS2404 PCR (+) & 86 & 8 & 94 & 81 & 13 & 94 & 54 & 40 & 94 \\
\hline IS2404 PCR (-) & 1 & 41 & 42 & 5 & 37 & 42 & 0 & 42 & 42 \\
\hline Total & 87 & 49 & 136 & 86 & 50 & 136 & 54 & 82 & 136 \\
\hline Disease prevalence & \multicolumn{3}{|c|}{$69.12 \%$ (60.63 to $76.75 \%)$} & \multicolumn{3}{|c|}{$69.12 \%(60.63$ to $76.75 \%)$} & \multicolumn{3}{|c|}{$69.12 \%(60.63$ to $76.75 \%)$} \\
\hline Sensitivity & \multicolumn{3}{|c|}{$91.49 \%$ (83.92 to $96.25 \%)$} & \multicolumn{3}{|c|}{$86.17 \%$ (77.51 to $92.43 \%)$} & \multicolumn{3}{|c|}{$57.45 \%$ (46.82 to $67.59 \%)$} \\
\hline Specificity & \multicolumn{3}{|c|}{$97.62 \%$ (87.43 to $99.94 \%)$} & \multicolumn{3}{|c|}{$88.10 \%$ (74.37 to $96.02 \%)$} & \multicolumn{3}{|c|}{$100.00 \%$ (91.59 to $100.00 \%)$} \\
\hline Positive Predictive Value & \multicolumn{3}{|c|}{$98.85 \%$ (92.53 to $99.83 \%)$} & \multicolumn{3}{|c|}{$94.19 \%$ (87.64 to $97.37 \%)$} & \multicolumn{3}{|c|}{$100 \%$} \\
\hline Negative Predictive Value & \multicolumn{3}{|c|}{$83.67 \%$ (72.50 to $90.88 \%)$} & \multicolumn{3}{|c|}{$74.00 \%$ (62.93 to $82.67 \%)$} & \multicolumn{3}{|c|}{$51.22 \%$ (45.36 to $57.04 \%)$} \\
\hline \multirow[t]{4}{*}{ Accuracy } & \multicolumn{3}{|c|}{$93.38 \%$ (87.81 to $96.93 \%)$} & \multicolumn{3}{|c|}{$86.76 \%$ (79.89 to $91.96 \%)$} & \multicolumn{3}{|c|}{$70.59 \%$ (62.17 to $78.09 \%)$} \\
\hline & \multicolumn{9}{|c|}{ LAMP WITH EasyNAT DNA EXTRACTS } \\
\hline & \multicolumn{3}{|c|}{ BURULI Primers } & \multicolumn{3}{|c|}{ MU 2404 Primers } & BU-I & Prime & \\
\hline & $(+)$ & $(-)$ & Total & $(+)$ & $(-)$ & Total & $(+)$ & $(-)$ & Total \\
\hline IS2404 PCR (+) & 70 & 10 & 80 & 59 & 21 & 80 & 38 & 42 & 80 \\
\hline IS2404 PCR (-) & 0 & 56 & 56 & 1 & 55 & 56 & 1 & 55 & 56 \\
\hline Total & 70 & 66 & 136 & 60 & 76 & 136 & 39 & 97 & 136 \\
\hline Disease prevalence & 58.82 & 07 to & & 58.82 & .07 to & & 58.8 & 07 to & \\
\hline Sensitivity & 87.50 & 21 to & & 73.75 & .71 to & & 47.5 & 21 to & \\
\hline Specificity & 100.0 & .62 to & & 98.2 & 45 to & & 98.2 & 45 to & \\
\hline Positive Predictive Value & $100 \%$ & & & 98.33 & 39 to & & 97.4 & 31 to & \\
\hline Negative Predictive Value & 84.85 & 82 to & & 72.37 & 42 to & & 56.7 & 46 to & \\
\hline Accuracy & 92.65 & 89 to & & 83.82 & 54 to & & 68.3 & 86 to & \\
\hline & LAM & H MO & EasyNA & EXTR & & & & & \\
\hline & BUR & mers & & MU & Prime & & BU- & Prime & \\
\hline & $(+)$ & $(-)$ & Total & $(+)$ & $(-)$ & Total & $(+)$ & $(-)$ & Total \\
\hline IS2404 PCR (+) & 64 & 7 & 71 & 59 & 12 & 71 & 25 & 46 & 71 \\
\hline IS2404 PCR (-) & 7 & 58 & 65 & 4 & 61 & 65 & 3 & 62 & 65 \\
\hline Total & 71 & 65 & 136 & 63 & 73 & 136 & 28 & 108 & 136 \\
\hline Disease prevalence & 52.21 & 48 to & & 52.2 & 48 to & & 52.2 & 48 to & \\
\hline Sensitivity & 90.14 & 74 to & & 83.10 & 34 to & & 35. & 24 to & \\
\hline Specificity & 89.23 & 06 to & & 93.85 & 99 to & & 95.3 & 10 to & \\
\hline Positive Predictive Value & 90.14 & 89 to & & 93.65 & 02 to & & 89.2 & 53 to & \\
\hline Negative Predictive Value & 89.23 & 32 to & & 83.56 & 15 to & & 57.4 & 97 to & \\
\hline Accuracy & 89.71 & 33 to & & 88.2 & 60 to & & 63.9 & 30 to & \\
\hline
\end{tabular}

modified Boom extraction method had the highest sensitivities. Thus, it is a good method for use in reference laboratories. However, the appropriateness of this method for confirmation of Buruli ulcer cases in resource limited settings should be cautiously explored, due to the requirements associated with it. It is not very practical for use in resource limited settings as it requires complex, lengthy procedures and sophisticated equipment. Thus, in terms of programmatic feasibility, testing requirements, time and cost, the modified EasyNAT method appears to be the best for field monitoring and evaluation programs, with sensitivities of 90.14 and $83.10 \%$ for the BURULI and MU 2404 primers respectively. These results also showed the BURULI to be best suited for analysis, since these gave the highest sensitivities, best predictive values and accuracies.

The aforementioned primers are both based on IS2404, while BU-LAMP primers are based on IS2606. 
Table 5 Detection limit of the LAMP tests with DNA extracted using QIAGEN, and visualized based on calcein detection system

\begin{tabular}{llll}
\hline $\begin{array}{l}\text { IS2404 } \\
\text { copy } \\
\text { numbers }\end{array}$ & \multicolumn{2}{l}{ Number positive per test } \\
\cline { 2 - 4 } & BURULI Primers & MU 2404 Primers & BU-LAMP Primers \\
\hline 300,000 & $1 / 1$ & $1 / 1$ & $1 / 1$ \\
30,000 & $1 / 1$ & $1 / 1$ & $1 / 4$ \\
3000 & $1 / 1$ & $1 / 1$ & $0 / 5$ \\
300 & $2 / 3$ & $2 / 3$ & $0 / 5$ \\
30 & $2 / 4$ & $1 / 4$ & $0 / 5$ \\
3 & $0 / 4$ & $0 / 4$ & $0 / 5$ \\
\hline
\end{tabular}

PCR assays based on IS2404 and IS2606 revealed that IS2606 PCR was 10 times less sensitive, compared to IS2404 PCR [13]. The copy numbers for the IS2404 and IS2606 target sequences in the genome of $M$. ulcerans strain Agy99 are 213 and 91 respectively [28], representing a little over twice as many copies of IS2404 compared to IS2606. These differences in copy numbers may explain why the IS2404 based primers resulted in a higher sensitivity.

\section{Conclusions}

The need for confirmation of Buruli ulcer cases requires tools that are sensitive. The results of this work would permit the development of improved tools for the diagnosis for Buruli ulcer. These assays, if adapted for field settings and poorly resourced laboratories, have the robustness and good turnaround times, to be used by 'semi-skilled' lab technicians with little supervision. For the development and use of future tests for Buruli diagnosis using the LAMP method, it is recommended that the BURULI primers [8] be used.

Table 6 Comparison of LAMP reactions using two different dyes, on DNA extracted using QIAGEN. Values in brackets represent the $95 \% \mathrm{Cl}$

\begin{tabular}{|c|c|c|c|c|c|c|c|c|c|c|c|}
\hline & \multicolumn{5}{|c|}{ BURULI Primers } & \multicolumn{6}{|c|}{ MU 2404 Primers } \\
\hline & \multicolumn{2}{|l|}{ Calcein } & \multicolumn{3}{|c|}{ HNB } & \multicolumn{3}{|c|}{ Calcein } & \multicolumn{3}{|c|}{ HNB } \\
\hline & $+\quad-$ & Total & + & - & Total & + & - & Total & + & - & Total \\
\hline $152404(+)$ & 548 & 62 & 55 & 7 & 62 & 54 & 8 & 62 & 57 & 5 & 62 \\
\hline IS2404 (-) & 142 & 43 & 2 & 41 & 43 & 4 & 39 & 43 & 4 & 39 & 43 \\
\hline Total & $55 \quad 50$ & 105 & 57 & 48 & 105 & 58 & 47 & 105 & 61 & 44 & 105 \\
\hline Positivity (\%) & \multicolumn{2}{|l|}{51.4} & \multicolumn{3}{|c|}{52.4} & \multicolumn{3}{|c|}{51.4} & \multicolumn{3}{|c|}{54.3} \\
\hline Sensitivity (\%) & \multicolumn{2}{|c|}{$\begin{array}{l}87.10 \text { (76.15 to } \\
94.26)\end{array}$} & \multicolumn{3}{|c|}{$\begin{array}{l}88.71 \text { (78.11 to } \\
95.34)\end{array}$} & \multicolumn{3}{|c|}{$\begin{array}{l}87.10(76.15 \text { to } \\
94.26)\end{array}$} & \multicolumn{3}{|c|}{$\begin{array}{l}91.94(82.17 \text { to } \\
97.33)\end{array}$} \\
\hline Specificity (\%) & \multicolumn{2}{|c|}{$\begin{array}{l}97.67 \text { (87.7 to } \\
99.94)\end{array}$} & \multicolumn{3}{|c|}{$\begin{array}{l}95.35 \text { ( } 84.19 \text { to } \\
99.43)\end{array}$} & \multicolumn{3}{|c|}{$\begin{array}{l}90.70 \text { (77.86 to } \\
97.41)\end{array}$} & \multicolumn{3}{|c|}{$\begin{array}{l}90.70 \text { (77.86 to } \\
97.41)\end{array}$} \\
\hline PPV (\%) & \multicolumn{2}{|c|}{$\begin{array}{l}98.18 \text { (88.59 to } \\
99.73)\end{array}$} & \multicolumn{3}{|c|}{$\begin{array}{l}96.49 \text { (87.63 to } \\
99.07)\end{array}$} & \multicolumn{3}{|c|}{$\begin{array}{l}93.10 \text { (84.08 to } \\
97.18)\end{array}$} & \multicolumn{3}{|c|}{$\begin{array}{l}93.44(84.82 \text { to } \\
97.32)\end{array}$} \\
\hline NPV (\%) & \multicolumn{2}{|c|}{$\begin{array}{l}84.00 \text { (73.30 to } \\
90.94)\end{array}$} & \multicolumn{3}{|c|}{$\begin{array}{l}85.42 \text { (74.40 to } \\
92.19 \text { ) }\end{array}$} & \multicolumn{3}{|c|}{$\begin{array}{l}82.98 \text { (71.71 to } \\
90.36)\end{array}$} & \multicolumn{3}{|c|}{$\begin{array}{l}88.64 \text { (77.00 to } \\
94.78)\end{array}$} \\
\hline Accuracy (\%) & \multicolumn{2}{|c|}{$\begin{array}{l}91.43 \text { (84.35 to } \\
96.01)\end{array}$} & \multicolumn{3}{|c|}{$\begin{array}{l}91.43(84.35 \% \\
\text { to } 96.01)\end{array}$} & \multicolumn{3}{|c|}{$\begin{array}{l}88.57 \text { ( } 80.89 \text { to } \\
93.95)\end{array}$} & \multicolumn{3}{|c|}{$\begin{array}{l}91.43 \text { (84.35 to } \\
96.01)\end{array}$} \\
\hline
\end{tabular}

\section{Abbreviations}

DNA: Deoxyribonucleic acid; LAMP: Loop mediated isothermal amplification; MU: Mycobacterium ulcerans; BU: Buruli ulcer; PCR: Polymerase chain reaction; SSD: Silica syringe device; HNB: Hydroxynapthol blue;

EDTA: Ethylenediaminetetraacetic acid; NMIMR: Noguchi memorial institute for medical research

\section{Acknowledgements}

The Authors will like to thank the Medical Doctors and Nurses for taking samples from Patients. We also thank the Patients for consenting to participate in the study.

\section{Authors' contributions}

Methodology, formal analysis, and writing - original draft preparation, review and editing, AA, EA, CAN, SAK, DKD; investigation and data creation, AA, DKD; conceptualization, project administration, and supervision, JMN, IC. All authors have read and approved the manuscript.

\section{Funding}

This study was supported by the Swiss Agency for Development and Cooperation and the UBS Optimus Foundation through FIND, GenevaSwitzerland. The funders had no role in the design of the study and collection, analysis, and interpretation of data and in writing the manuscript.

\section{Availability of data and materials}

The datasets used and/or analysed during the current study are available from the corresponding author on reasonable request.

\section{Declarations}

\section{Ethics approval and consent to participate}

This study was carried out at the Noguchi Memorial Institute for Medical Research (NMIMR), University of Ghana. Clinical samples were taken at the hospital or health centres as part of the routine diagnostic procedure and case confirmation recommended by WHO, and sent to the NMIMR for analysis. Ethical approval for collection and use of patients' samples was obtained from the Institutional Review Board of the NMIMR (Study number NMIMR-IRB CPN 024/18-19). Patients were required to sign an informed consent. To ensure anonymity, personal information such as names, and other personal identifiers associated with patient's samples were replaced with codes.

\section{Consent for publication}

Not applicable

\section{Competing interests}

The authors declare no conflict of interest.

\section{Author details}

${ }^{1}$ Noguchi Memorial Institute for Medical Research, College of Health Sciences, University of Ghana, Legon, Accra, Ghana. ${ }^{2}$ Foundation for Innovative New Diagnostics, Geneva, Switzerland. ${ }^{3}$ National School of Public Health, Instituto de Salud Carlos III, Madrid, Spain.

Received: 5 November 2020 Accepted: 10 June 2021

Published online: 23 June 2021

\section{References}

1. World Health Organization. Buruli ulcer disease: Mycobacterium ulcerans infection: an overview of reported cases globally. Wkly Epidemiol Rec. 2004; 79:194-9 https://apps.who.int/iris/handle/10665/232478.

2. World Health Organization. Buruli ulcer: progress report, 2004-2008. Wkly Epidemiol Rec. 2008;83:145-54 https://apps.who.int/iris/handle/1 0665/241134.

3. Johnson PDR. Buruli Ulcer in Australia. In: Pluschke G, Röltgen K, editors. Buruli Ulcer: Mycobacterium Ulcerans Disease. Cham: Springer International Publishing; 2019. p. 61-76. https://doi.org/10.1007/978-3-030-11114-4_3.

4. World Health Organization. Buruli ulcer (Mycobacterium ulcerans infection). 2019. https://www.who.int/news-room/fact-sheets/detail/buruli-ulcer(mycobacterium-ulcerans-infection). Accessed 8 Oct 2020. 
5. Sizaire V, Nackers F, Comte E, Portaels F. Mycobacterium ulcerans infection control, diagnosis, and treatment. Lancet Infect Dis. 2006;6(5):288-96. https://doi.org/10.1016/S1473-3099(06)70464-9.

6. Beissner M, Herbinger K-H, Bretzel G. Laboratory diagnosis of Buruli ulcer disease. Future Microbiol. 2010;5:363-70. https://doi.org/10.2217/fmb.10.3.

7. World Health Organization. Cotonou declaration on buruli ulcer. Geneva PP - Geneva: World Health Organization; 2009. https://apps.who.int/iris/ha ndle/10665/329410

8. Ablordey A, Amissah DA, Aboagye IF, Hatano B, Yamazaki T, Sata T, Ishikawa K, Katano $\mathrm{H}$ Detection of Mycobacterium ulcerans by the loop mediated isothermal amplification method. PLoS Negl Trop Dis 2012;6:e1590. https:// doi.org/https://doi.org/10.1371/journal.pntd.0001590, 4.

9. Asiedu K, Wansbrough-Jones M. Mycobacterium ulcerans infection (Buruli or Bairnsdale ulcer): challenges in developing management strategies. Med J Aust. 2007;186:55-6 http://europepmc.org/abstract/MED/17223762.

10. Bretzel G, Huber KL, Kobara B, Beissner M, Piten E, Herbinger K-H, et al. Laboratory confirmation of Buruli ulcer disease in Togo, 2007-2010. PLoS Negl Trop Dis. 2011;5(7):e1228. https://doi.org/10.1371/journal.pntd.0001228.

11. Johnson PDR, Azuolas J, Lavender CJ, Wishart E, Stinear TP, Hayman JA, et al. Mycobacterium ulcerans in mosquitoes captured during outbreak of Buruli ulcer, southeastern Australia. Emerg Infect Dis. 2007;13(11):1653-60. https://doi.org/10.3201/eid1311.061369.

12. Ross BC, Marino L, Oppedisano F, Edwards R, Robins-Browne RM, Johnson PD. Development of a PCR assay for rapid diagnosis of Mycobacterium ulcerans infection. J Clin Microbiol. 1997;35(7):1696-700. https://doi.org/1 0.1128/JCM.35.7.1696-1700.1997.

13. Stinear T, Ross BC, Davies JK, Marino L, Robins-Browne RM, Oppedisano F, et al. Identification and characterization of IS2404 and IS2606: two distinct repeated sequences for detection of Mycobacterium ulcerans by PCR. J Clin Microbiol. 1999;37(4):1018-23. https://doi.org/10.1128/JCM.37.4.1018-1023.1 999.

14. Iwamoto T, Sonobe T, Hayashi K. Loop-mediated isothermal amplification for direct detection of Mycobacterium tuberculosis complex, M. avium, and M. intracellulare in sputum samples. J Clin Microbiol. 2003;41(6):2616-22. https://doi.org/10.1128/jcm.41.6.2616-2622.2003.

15. Notomi T, Okayama H, Masubuchi H, Yonekawa T, Watanabe K, Amino N, et al. Loop-mediated isothermal amplification of DNA. Nucleic Acids Res. 2000;28(12) 63e, 663:E63. https://doi.org/10.1093/nar/28.12.e63.

16. de Souza DK, Quaye C, Mosi L, Addo P, Boakye DA. A quick and cost effective method for the diagnosis of Mycobacterium ulcerans infection. BMC Infect Dis. 2012;12(1):8. https://doi.org/10.1186/1471-2334-12-8.

17. Goto M, Honda E, Ogura A, Nomoto A, Hanaki K-I. Colorimetric detection of loop-mediated isothermal amplification reaction by using hydroxy naphthol blue. Biotechniques. 2009;46(3):167-72. https://doi.org/10.2144/000113072.

18. Aonuma H, Yoshimura A, Perera N, Shinzawa N, Bando H, Oshiro S, et al. Loop-mediated isothermal amplification applied to filarial parasites detection in the mosquito vectors: Dirofilaria immitis as a study model. Parasit Vectors. 2009;2(1):15. https://doi.org/10.1186/1756-3305-2-15.

19. Njiru ZK, Mikosza ASJ, Matovu E, Enyaru JCK, Ouma JO, Kibona SN, et al. African trypanosomiasis: sensitive and rapid detection of the sub-genus Trypanozoon by loop-mediated isothermal amplification (LAMP) of parasite DNA. Int J Parasitol. 2008;38(5):589-99. https://doi.org/10.1016/j.ijpara.2007. 09.006.

20. Pandey BD, Poudel A, Yoda T, Tamaru A, Oda N, Fukushima Y, et al. Development of an in-house loop-mediated isothermal amplification (LAMP) assay for detection of Mycobacterium tuberculosis and evaluation in sputum samples of Nepalese patients. J Med Microbiol. 2008:57(Pt 4):439_ 43. https://doi.org/10.1099/jmm.0.47499-0.

21. Parida M, Posadas G, Inoue S, Hasebe F, Morita K. Real-time reverse transcription loop-mediated isothermal amplification for rapid detection of West Nile virus. J Clin Microbiol. 2004;42(1):257-63. https://doi.org/10.1128/ jcm.42.1.257-263.2004.

22. Poon LLM, Wong BWY, Ma EHT, Chan KH, Chow LMC, Abeyewickreme W, et al. Sensitive and inexpensive molecular test for falciparum malaria: detecting plasmodium falciparum DNA directly from heat-treated blood by loop-mediated isothermal amplification. Clin Chem. 2006;52(2):303-6. https://doi.org/10.1373/clinchem.2005.057901.

23. Njiru ZK, Yeboah-Manu D, Stinear TP, Fyfe JAM. Rapid and sensitive detection of Mycobacterium ulcerans by use of a loop-mediated isothermal amplification test. J Clin Microbiol. 2012;50(5):1737-41. https://doi.org/10.112 8/JCM.06460-11.
24. Eddyani M, Fraga AG, Schmitt F, Uwizeye C, Fissette K, Johnson C, et al. Fine-needle aspiration, an efficient sampling technique for bacteriologica diagnosis of nonulcerative Buruli ulcer. J Clin Microbiol. 2009;47(6):1700-4. https://doi.org/10.1128/JCM.00197-09.

25. Yeboah-Manu D, Danso E, Ampah K, Asante-Poku A, Nakobu Z, Pluschke G. Isolation of \&lt;span class=\&quot;named-content genus-species\&quot; id= \&quot;named-content-1\&quot;\&gt;Mycobacterium ulcerans\&lt;/span\&gt; from swab and fine-needle-aspiration specimens. J Clin Microbiol. 2011;49: 1997 LP - 1999. doi:https://doi.org/10.1128/JCM.02279-10.

26. Suebsing R, Kampeera J, Sirithammajak S, Withyachumnarnkul B, Turner W, Kiatpathomchai W. Colorimetric method of loop-mediated isothermal amplification with the pre-addition of Calcein for detecting Flavobacterium columnare and its assessment in Tilapia farms. J Aquat Anim Health. 2015; 27(1):38-44. https://doi.org/10.1080/08997659.2014.966212.

27. Hennekens $\mathrm{CH}$, Buring JE, Mayrent SL. Epidemiology in medicine. Boston, Massachusetts: Little, Brown; 1987.

28. Stinear TP, Seemann T, Pidot S, Frigui W, Reysset G, Garnier T, et al. Reductive evolution and niche adaptation inferred from the genome of Mycobacterium ulcerans, the causative agent of Buruli ulcer. Genome Res. 2007;17(2):192-200. https://doi.org/10.1101/gr.5942807.

\section{Publisher's Note}

Springer Nature remains neutral with regard to jurisdictional claims in published maps and institutional affiliations.
Ready to submit your research? Choose BMC and benefit from:

- fast, convenient online submission

- thorough peer review by experienced researchers in your field

- rapid publication on acceptance

- support for research data, including large and complex data types

- gold Open Access which fosters wider collaboration and increased citations

- maximum visibility for your research: over $100 \mathrm{M}$ website views per year

At BMC, research is always in progress.

Learn more biomedcentral.com/submissions 